\section{No rastro de Piero}

Carlo GINZBURG. Investigando Piero: o Batismo, o ciclo de Arezzo, a Flagelação de Urbino. Trad. Denise Bottmann. São Paulo, Cosac Naify, 2010. 312 páginas.

\section{Luis Felipe Sobral*}

O historiador italiano Carlo Ginzburg, especialista em processos da Inquisição do início da Era moderna, interpretados na chave da circularidade entre cultura erudita e cultura popular, é autor de uma obra focada na história da cultura em escala ampliada. Em Investigando Piero, livro que inaugurou, em 1981, a célebre coleção Microstorie, organizada na editora Einaudi pelo próprio Ginzburg e pelo historiador conterrâneo Giovanni Levi, ele enfrenta uma questão cara à história da arte: o problema de datação da obra do pintor toscano Piero della Francesca (c. 1416-1492). Sua proposta consiste em analisar as principais obras de Piero a partir de um duplo ponto de vista: o comissionamento e a iconografia. Essa análise circunscrita e microscópica - ele jamais perde de vista o objeto artístico - não pretende avançar pelo terreno estilístico, mas ambiciona "desenhar uma imagem de Piero diferente da estabelecida” (p. 21); ela é possível, em grande medida, devido à pobreza dos dados biográficos sobre o artista. A abordagem de Ginzburg propõe uma articulação complexa entre a obra de arte e o contexto social em que ela nasceu; daí o uso que faz da relação entre morfologia e história: uma vez que a arte apresenta uma autonomia relativa diante da vida social, esta não pode determinar aquela. Como passar de uma dimensão à outra?

No quarto e último capítulo de Investigando Piero, Ginzburg sublinha a importância iconográfica de identificar a presença de retratos de personagens contemporâneos na Flagelação de Cristo. " "É absolutamente certo que o homem ajoelhado aos pés da Nossa Senhora da Misericórdia ${ }^{2}$ e o homem

* Agradeço a Carlo Ginzburg e Rodrigo Ramassote pela leitura e comentários. A edição resenhada consiste na segunda tradução brasileira; a primeira (Indagações sobre Piero. Trad. Luiz Carlos Cappellano, Rio de Janeiro, Paz e Terra, 1989) não inclui certas modificaçôes no corpo do livro nem os quatro apêndices que retomam discussões pontuais. com manto de brocado da Flagelação são a mesma pessoa" (p. 100), afirma o autor; para tanto, pauta-se em um pentimento, presente nos dois quadros, utilizado para reduzir ligeiramente as dimensões do crânio do personagem; tais pentimentos só podem ter finalidade retratística, argumenta.

No entanto, o mesmo personagem foi pintado por Piero uma terceira vez: num dos afrescos de Arezzo. Numa nota que, salvo engano meu, escapou aos sucessivos estudiosos, [o historiador da arte inglês Kenneth] Clark destacou que, mesmo sendo notoriamente arriscada a identificação das semelhanças, é indubitável que o homem de perfil à esquerda de Cosroés $\left.{ }^{3}\right]$ corresponde, apenas um pouco mais avantajado devido à idade, ao homem representado aos pés da Nossa Senhora da Misericórdia. Ao comparar esta àquela outra identificação, não mencionada por Clark, do homem com manto de brocado na Flagelação, devemos concluir que se trata do mesmo indivíduo nos três casos. Basta observar o pescoço largo marcado por uma profunda dobra, o queixo, a boca, os olhos e, em especial, a singularissima orelha, de ponta aguda e cortada, e o lóbulo carnudo (pp. 100-101, grifo meu).

Quem seria esse personagem três vezes retratado por Piero? Ora, com base em um documento de autoria do pintor e historiador da arte Giorgio Vasari (1511-1574), Ginzburg chega à conclusão de que, em torno do Cosroés derrotado, Piero pintou os comitentes do ciclo de Arezzo, do qual esse afresco faz parte, isto é, os representantes de três gerações da família Bacci, ricos comerciantes de especiarias; da direita para a esquerda, vê-se: Baccio, que estabeleceu a encomenda em 5 de agosto de 1416, seu filho Francesco, que deu início à obra em 1447, e seu neto Giovanni, que a supervisionou até o fim. Portanto, a identidade fisionômica entre o comitente de perfil atrás de Cosroés e o homem com manto de brocado da Flagelação indica que o personagem é Giovanni Bacci, que vivia nos círculos humanistas e era ligado à família Medici; tendo se laureado em direito em Siena, foi clérigo da Câmara Apostólica, onde caiu em desgraça, empre- 
endendo a seguir uma carreira nas cortes da Itália centro-setentrional.

A identificação de Giovanni Bacci como o homem do manto de brocado é fundamental para avançar uma interpretação sobre a Flagelação, sobre a qual a única informação indiscutível é sua autografia. Trata-se de um quadro enigmático, no qual se vê, em segundo plano e à esquerda, o episódio da flagelação de Cristo e, em primeiro plano e à direita, três figuras misteriosas distanciadas da primeira cena graças à virtuosidade da perspectiva. Quem são tais figuras? Qual a relação entre elas e o episódio bíblico ao fundo? O que exatamente Piero quis representar nesse quadro? Sem embargo, "todo o jogo referente à Flagelação se dá no plano da decifração da iconografia", afirma o autor (p. 97). Se quarenta anos de discussão não produziram nenhum consenso sobre a Flagelação, ao menos delinearam duas teses gerais: de um lado, ela se aloja em uma série iconográfica preexistente relacionada com a paixão de Cristo; de outro, trata-se de uma iconografia anômala, referente a acontecimentos políticos e religiosos contemporâneos que mantêm uma relação simbólica com a paixão de Cristo. Não se trata aqui de reconstituir todo o argumento de Ginzburg, esforço vão que acabaria apenas arrebatando toda a graça do livro, pautada no fio narrativo que persegue uma série de indícios; basta dizer que sua interpretação segue o caminho da segunda tese.

De fato, o que interessa é notar a expressão grifada no excerto transcrito ("a singularíssima orelha"), pois ela conduz a uma discussão sobre o método de Ginzburg. A forma da orelha da figura três vezes retratada por Piero é o indício inconteste de que se está diante da mesma pessoa, pois sabe-se que, do ponto de vista anatômico, cada orelha é única: o pintor não a teria replicado - ainda mais com características morfológicas singulares - caso não se tratasse do mesmo indivíduo. Tal raciocínio remete a dois personagens oitocentistas. O primeiro é o colecionador e historiador da arte (além de político e escritor) italiano Giovanni Morelli (1819-1891), que propôs um novo método para o estabelecimento da autoria de um quadro: o olhar do connaisseur não deveria se deter sobre os traços característicos de um pintor, uma vez que esses eram particularmente objetos de escrutínio dos falsários, mas sim sobre traços negligenciáveis, como detalhes anatômicos. ${ }^{4} \mathrm{O}$ segundo é o detetive fictício Sherlock Holmes, que se depara com um caso bizarro: uma pacata inglesa recebe pelo correio um par de orelhas humanas; após entrevistá-la, Holmes resolve o mistério pela forma de uma das orelhas enviadas, idêntica à orelha da destinatária. ${ }^{5} \mathrm{Em}$ ambos os casos, procede-se dos efeitos pelas causas, isto é, a forma de certos detalhes anatômicos permite a reconstrução de uma série de eventos organizados em uma sequência narrativa que desvenda as autorias de um quadro ou de um crime. O ponto fundamental é compreender que, sem o controle exercido pelos dados externos, a pista formal é, na melhor das hipóteses, inútil e, na pior, equivocada: o connaisseur não pode concluir que tal orelha indica a autoria de Piero sem conhecer não apenas outros quadros do pintor, mas também como a pintura era então praticada; Holmes só chega à solução do caso depois de entrevistar a destinatária da insólita caixa de papelão, ou seja, após se colocar a par de um contexto para as orelhas decepadas; Ginzburg precisa de fontes externas ao quadro para identificar seu personagem como Giovanni Bacci. Em suma, para que o procedimento dito morfológico conduza a conclusões inacessíveis por outros caminhos, ele deve ser circunscrito ao estatuto de pista contextualizada, isto é, relacionada com a história.

Morelli e Holmes formam, com Sigmund Freud, a tríade do chamado paradigma indiciário, um modo de conhecimento que remonta aos primeiros caçadores, obrigados a interpretar os rastros deixados por suas presas e a formular tais interpretações em uma forma narrativa que reconstruísse a trajetória do animal. Em um importante artigo publicado em 1979, ${ }^{6}$ Ginzburg descreve esse modelo cognitivo e o acompanha em suas diversas manifestaçoes, desde sua forma venatória, passando pela medicina hipocrática, pela filologia, pela invenção da impressão digital, até sua configuração oitocentista com os contemporâneos Morelli, Holmes e Freud: "Nos três casos, pistas talvez infinitesimais permitem captar uma realidade mais profunda, de outra forma inatingível. Pistas: mais precisamente, sintomas (no caso de Freud), indícios (no caso de 
Sherlock Holmes), signos pictóricos (no caso de Morelli)". 7 Nessa duração histórica longuíssima, se, por um lado, a multiformidade desse modo de conhecimento produz versões distintas, nomeadas conforme seus contextos (venatório, divinatório, indiciário, semiótico), por outro, se reconhece um modelo epistemológico comum, pautado na distância temporal entre o fenômeno e o observador e na interpretação de indícios organizada em uma forma narrativa capaz, em certa medida, de reconstruir o fenômeno. Nesse sentido, o paradigma indiciário consiste em um saber indireto e conjectural, tornando-o vulnerável aos critérios de cientificidade de disciplinas hegemônicas, como a física galileana, para a qual os fenômenos individuais são inefáveis; tal vulnerabilidade o manteve à margem até o final do século XIX. Trata-se de uma modalidade de conhecimento cuja ambição é superar a oposição entre subjetividade e objetividade, pois se, de um lado, depende de forma decisiva da experiência do pesquisador ("faro", "golpe de vista”), dimensão aliás que é parte integrante da exposição dos resultados da pesquisa, de outro, se vale da prova como elemento de controle, definida, no jogo entre conjecturas e refutaçōes, por uma dupla recusa: nem um acesso imediato à realidade, nem um universo completamente autônomo. Retomo então a questão de Ginzburg no final de seu artigo: "pode um paradigma indiciário ser rigoroso?" " No âmbito do livro resenhado, a resposta passa necessariamente pela interlocução e pelo limite desse procedimento detetivesco.

Em Investigando Piero, o principal interlocutor de Ginzburg é o historiador da arte italiano Roberto Longhi (1890-1970), autor de um estudo sobre Piero publicado em 1927 e que se tornou referência na disciplina. ${ }^{9}$ Trata-se de uma écfrase, elaborada cronologicamente em estilo elevado, da obra do pintor quatrocentista, o que pressupõe, da perspectiva histórica, o encontro de certo crítico, munido de uma cultura visual particular, com uma série circunscrita de objetos artísticos..$^{10}$ Ora, ao longo dessa descrição, que se detém, conforme o termo do autor, sobre a "personalidade pictórica" de Piero, e que ocupa cerca de oitenta páginas, o leitor não encontrará nenhuma palavra a respeito da figura histórica do pintor, pois tal informação se encontra na série de apêndices (dados biográficos, fortuna histórica, notas, comentários sobre as ilustrações). Tudo se passa como se Longhi quisesse criar um mundo de formas puras, onde seu olho treinado traduzisse em palavras sublimes a evolução estilística do artista; no entanto, tal ambição só é exequível na medida em que se apoia nos indispensáveis dados históricos consumidos, a ponto de não deixar vestígios, pela virtuosidade descritiva: o esforço formalista cria uma aparente, porém enganosa, descontinuidade entre o Piero "pictórico" e o Piero "histórico". Esse artifício torna-se mais sofisticado conforme o autor acrescenta um breve ensaio, "Piero em Arezzo", e amplia os apêndices, na segunda (1942) e terceira (1963) ediçôes, tornando-os equivalentes em extensão ao corpo do livro e dando a impressão, segundo as palavras de Ginzburg, de um "canteiro de obras que se prolongam há décadas". ${ }^{11}$

No quarto e último apêndice de seu livro, igualmente dividido em quatro capítulos que tratam das três obras indicadas no subtítulo, sendo que à Flagelação são dedicados os dois últimos, Ginzburg explica que o trabalho de Longhi repousa na coexistência de uma dupla abordagem, descrita também como morfologia e história, porém articulada de outra maneira. Apesar de Longhi ter mostrado que o exame pictórico minucioso da obra de Piero pode contornar, em certa medida, a escassez da documentação externa sobre o pintor toscano, e ter empreendido ocasionalmente demonstraçôes históricas, isto é, argumentos que dependem da convergência de várias séries não estilísticas, e não apenas de uma exposição oriunda exclusivamente da sensibilidade às formas, sua obra conferiu à história, diante de uma morfologia entendida como "um inventário articuladíssimo de formas" (p. 275), uma função instrumental: a história que escreveu é uma história das formas que se queria independente da vida social. Entre a juventude e a maturidade de Longhi, essa postura formalista radical seria suavizada (p. 26).

No segundo apêndice, o rigor e o limite do paradigma indiciário, esse modo singular de fazer pesquisas, ficam evidentes. Diante de interpretações iconográficas muito divergentes elaboradas pelos estudiosos sobre a Flagelação, Ginzburg refuta a postura cética que defende que qualquer interpretação a 
respeito de uma pintura (ou um texto) seja possível; para tanto, vale-se de suas pesquisas sobre o quadro de Piero "para analisar os limites da prova no campo dos estudos sobre a iconografia” (p. 245). A partir da distinção rigorosa entre prova e conjectura, ele aloja sua leitura da Flagelação na segunda categoria: a cena em primeiro plano representaria uma importante viagem de Giovanni Bacci a Constantinopla, na condição de núncio pontifício, para comunicar a Bessarion, o homem de barba bipartida à esquerda, sua nomeação cardinalícia; apesar de não haver nenhum documento que comprove essa viagem, tal leitura repousava, em certa medida, na longa faixa vermelha que se vislumbra sobre o ombro direito e próxima ao tornozelo de Bacci, símbolo do cardinalato. Ora, o significado dessa faixa, inferido com base na iconografia de São Jerônimo, representado geralmente com atributos cardinalícios, mostrou-se equivocado: trata-se na verdade de um bechetto, "uma longa tira cujas pontas pendiam como uma espécie de turbante, amplamente usado na Itália quatrocentista” (p. 258). Inicialmente promissora, tal pista remeteu novamente a interpretação de Ginzburg ao plano conjectural; no entanto, é justamente na relação entre conjecturas e refutações - vale dizer: através de experimentos sucessivos - que se vislumbram as provas de hipóteses arriscadas, sem as quais o conhecimento se empobrece.

Investigando Piero, a exemplo do Piero della Francesca de Longhi, atravessou três ediçôes, o acréscimo de quatro apêndices, redigidos entre 1982 e 1993, e incontáveis discussões: eis os sintomas do desafio de seguir esse fugidio pintor quatrocentista, cujos rastros históricos se circunscrevem, em grande medida, aos seus quadros. Desse ponto de vista, uma única conclusão persiste: distante da vida social, o mundo das formas é um universo traiçoeiro.

\section{Notas}

1 Piero della Francesca, Flagelação de Cristo. Urbino, Galleria Nazionale delle Marche.

2 Piero della Francesca, Nossa Senhora da Misericórdia. Sansepolcro, Museo Civico.

3 Piero della Francesca, Derrota de Cosroés. Arezzo, San Francesco.
4 Jaynie Anderson, "Morelli, Giovanni", The dictionary of art. Ed. Jane Turner. Londres, Macmillan, 1996, vol. 22, pp. 101-103. Segundo Ginzburg, o argumento que conduz à identificação de Giovanni Bacci como o personagem pintado por Piero não é propriamente um argumento morelliano, uma vez que, para Morelli, todas as orelhas pintadas por um artista se assemelham, isto é, a forma pictórica é produto de uma grafia pessoal e portanto única.

5 Arthur Conan Doyle, "The Cardboard Box", The new annotated Sherlock Holmes. Ed. Leslie S. Klinger. Nova York, W. W. Norton, 2005, vol. 1, pp. 422-448.

6 C. Ginzburg, "Spie: radici di un paradigma indiziario", Crisi della ragione: nuovi modelli nel rapporto tra sapere e attività umane. Turim, Einaudi, 1979, pp. 59106 [trad. brasileira: "Sinais: raízes de um paradigma indiciário", Mitos, emblemas, sinais: morfologia e história. Trad. Federico Carotti. São Paulo, Companhia das Letras, 1989, pp. 143-179.

7 Idem, p. 150.

$8 \quad$ Idem, p. 178.

9 Roberto Longhi, Piero della Francesca. Trad. D. Bottmann. São Paulo, Cosac Naify, 2007.

10 C. Ginzburg, "Introdução", em R. Longhi, op. cit., pp. 7-8.

11 Idem, p. 7.

\section{LUÍS FELIPE SOBRAL é doutorando em Antropologia Social na Unicamp sob orientação de Heloisa Pontes. E-mail: <lfsobral@yahoo.com>.}

